\title{
Business Process Adoption in Organisations: A Case Study from an Insurance Company in South Africa
}

\author{
Sikho LUZIPO ${ }^{1}$, Judy VAN BILJON ${ }^{2}$, Marlien HERSELMAN, ${ }^{3}$ \\ ${ }^{1,2,3}$ University of South Africa, Science Campus, Johannesburg, 1709, South Africa \\ Tel: +27670 9182, ${ }^{1}$ Email: luzipoms@gmail.com, ${ }^{2}$ Email:vbiljja@unisa.ac.za \\ ${ }^{3}$ CSIR - Meraka Institute, P.O Box 395, Pretoria, 0001, South Africa \\ Tel: +27(0)12 841 3081, Fax: + 27(0)12 841 4720, ${ }^{3}$ Email: mherselman@csir.co.za
}

\begin{abstract}
Business process adoption is one of the factors that determine an organisation's performance. While there are various factors that can have an impact on business processes adoption, this paper focuses on the impact of individual, process and organisational factors when adopting business processes in a large insurance organisation. Given evidence of non-optimal adoption, this paper investigates the factors that affect the adoption of business process by employees in insurance organisations in the context of Information Technology (IT) software development projects. A case study methodology was used with one large insurance company in South Africa as the unit of analysis. The data collection process started with conducting interviews with eight business process analysts to gain an understanding of how business processes are used in this organisation. This was followed by an online survey targeted at 120 business process users for which 65 responses were received. From the results of this study, a business process adoption (BPA) model has been developed which can be applied to assist an insurance organisation to improve the adoption of its business processes. The factors proposed in the model could guide future initiatives that aim to ensure the success of business processes in organisations.
\end{abstract}

Keywords: Business processes, adoption, insurance organisations.

\section{Introduction}

The performance of an organisation depends, among other things, on the effectiveness of its business processes since each business process can either increase or decrease the performance [15]. The introduction of a new technology in an organisation is usually accompanied by changes in business processes. However, providing business process support for technological changes in organisations is a challenging task [34]. Chan [10] suggests that, for business processes, IT can act as an initiator, facilitator and enabler of business processes.

This implies that there are similarities between adopting technologies and adopting business processes and thus it is useful to consider the technology adoption literature as a point of departure. This study was conducted in one of the largest insurance organisations in South Africa. The organisation has been experiencing non-optimal adoption of its business processes. Table 1 provides a summary of the defects in business process adherence that was identified in this organisation between August 2013 and March 2014. 
Table 1: Business Process Adherence

\begin{tabular}{|l|l|l|l|}
\hline Team & $\begin{array}{l}\text { Business Process } \\
\text { executions }\end{array}$ & Defects & Defect \% \\
\hline Commissions & 13833 & 515 & $3.71 \%$ \\
\hline Finance & 1274 & 24 & $2 \%$ \\
\hline New Business \& Underwriting & 30011 & 988 & $3.4 \%$ \\
\hline Servicing & 13352 & 1021 & $8.72 \%$ \\
\hline Call Centre & 11101 & 394 & $3.72 \%$ \\
\hline Claims & 460 & 9 & $1.25 \%$ \\
\hline
\end{tabular}

The number of defects varies between $1.25 \%$ and $8.72 \%$ with an average of 3.8 defects. The results are considered unacceptably high since this organisation is aiming for $0 \%$ defect. Besides this example of non-optimal business process adoption in an insurance organisation a general problem with business process adoption has been highlighted by Weber, Mutschler and Reichert [35] and Chan [10]. Therefore the aim of this study is to identify the factors that affect the adoption of business processes in insurance organisations. Venkatesh [29] points out that even though users may have freedom with regards to technology usage -they do not have the same freedom with regards to business processes adoption. Bala [8] argues that previous research on technology enabled processes has predominantly been focused on macro-level issues with limited focus on micro-level impact on the users who have to execute the process. Therefore, this study focuses on individual adoption of business processes by employees following an introduction of a new technology or changes to an existing technology.

The research is guided by the following research question: What are the factors that influence the adoption of business processes by employees in insurance organisations?

The study is organized as follows. The objectives of the study are outlined in section 2 , followed by the methodology in section 3 . In section 4, a brief review of the literature on business processes and technology adoption is presented. An initial model for business process adoption is proposed as a point of departure presented in section 5 . The results of the study are discussed in section 6 followed by business benefits of the study in section 7 with the conclusion in section 8 .

\section{Objectives}

This study sought to achieve three main objectives:

1. To investigate the characteristics of business processes in an insurance organisation.

2. To identify the factors that influences the adoption of technologies in relation to business processes in an insurance organisation.

3. To develop a model of the factors that influences the adoption of business processes in organisations.

\section{Methodology}

This study applied a case study research approach. The data was collected through interviews (to understand the usage of business processes) and a survey (to identify the factors that are most likely to affect business process adoption).

\subsection{Research Setting and Sampling}

The research was designed to take place in a single case study site. This research was conducted with participants from one of the largest insurance organisations in South Africa. 
A purposive sampling technique was applied for data collection in this study for both interviews and the survey.

\subsection{Questionnaire Design}

The questionnaire for one-on-one semi-structured interviews contained nine questions which were related to the variables being investigated. The questionnaire for the survey consisted of forty-three items that were presented in a five point Likert scale. Participants were asked to rate the extent to which they agree (strongly agree, agree, neither agree nor disagree, disagree and strongly disagree) with each of the statements that were presented to them.

\section{Technology Description}

This section provides the background on the two theoretical perspectives that were used to understand the adoption of business processes by employees, namely business processes (section 2.1) and technology adoption (2.3).

\subsection{Business Processes}

Business processes are at the core of Business Process Management (BPM) which is a management discipline that strives to understand the mechanics of business with the purpose of improving or radically changing them [19]. According to Lohmann [20], business processes are the main asset of the organisation as they define the way business is conducted. Numerous definitions of business processes can be found in the literature (see $[12,25]$ and [34]). The definition that was adopted in this study is by Strnadl [28] who defined business process as "a complete, dynamically coordinated set of collaborational and transactional activities that (1) delivers value to customers or (2) fulfils other strategic goals of the enterprise" [28:70]. This definition highlights the importance of business processes in delivering value to customers and achieving business and organisational objectives. Organisations adopt a process centric approach to achieve different objectives based on their view of business processes.

Even though there are different types of business processes mentioned in the literature, there seems to be consensus on three types i.e. management processes, operational processes and support processes. These three types are discussed next:

Management Processes: these are business processes that are responsible for the governing of the organisation; they are concerned with future performance of the organisation [9].

Operational processes: these are processes that create primary value stream for the organisation. Gaivin [15] suggested that these processes are responsible for producing the products and services for the customer. Operational processes define the way in which work gets done [4], it is the transformation of input (raw material) to outputs (products or service).

Supporting processes: these are processes that are aimed at supporting the core functions of the organisation. They enable operational processes [6]. Example of these processes could be recruitment processes and technical support.

Even though organisations apply different types of business processes, they all share the same characteristics which are discussed in the next section.

\subsubsection{Characteristics of Business Processes}

Business processes are cross-functional, inter-departmental and global by nature hence they are considered unique [8]. Some of the characteristics of business processes are: 
1. Business processes have a clearly defined outcome. The aim of a business process is to achieve a goal that involves the delivery of a product or a service [5].

2. Business processes have customers or users. Scherr [25] suggests that one of the first questions to be addressed when defining business processes is to establish who the ultimate customer is, who must be satisfied with the execution of the business process?

3. Business processes have a beginning and an end. Every business process has a beginning that is always caused by a certain event [17] and has an observable outcome, either a service or a product [6]. Business processes usually end with a fulfilled customer need [27].

4. Business processes have rules. Rules define the manner in which activities of the business processes must be executed [9].

5. Business processes have activities. A business processes is a representation of a group of one or more activities [17]. Activities are specific tasks that need to be executed for the business process to be completed.

\subsection{Technology Adoption}

Research on technology acceptance and usage in organisations is mature. Technology adoption has been studied at individual, organisational, societal and at group level. For the purpose of this paper we will use the terms acceptance and adoption interchangeably although we acknowledge that there are subtle differences. Previous studies on technology adoption have focused on an individual's characteristics (e.g. Davis, Bagozzi, \& Warshaw [14]; Venkatesh, Morris, Davis, \& Davis [33]; Hess, Joshi \& McNab [18]) technology's characteristics (e.g. Davis [13]; Venkantesh and Davis [31]) and organisational characteristics (e.g. Davis [13]) as the key factors that determine the acceptance of technologies. Visser, van Biljon \& Herselman [33] provided a summary of the most commonly used models to study technology adoption and usage. Despite different foci, all the models are based on the same concept - individual end users of technology will have different reactions to using new technology depending on a variety of factors. One of the most popular models is Technology Acceptance Model (TAM) which was proposed by Davis [13]. TAM is based on the belief that users accept or reject a new technologies based on the extent they believe it will help them perform their job better (perceived usefulness) and also on the degree to which they believe that the usage of the technology will be free of effort (perceived ease of use). Business processes are driven by technology. Business process users, like technology users are faced with the decision to adopt and use optimally or not. The adoption decision is influenced by determining factors, i.e. usefulness, ease of use and facilitating factors like infrastructure [32]. Even where usage is mandatory, users may vary in their intention and level of adoption and use. The similarities between business process adoption and technology adoption form the basis of our argument that technology adoption models are relevant in explaining business process adoption. Therefore this paper leverages on some of the existing individual technology adoption variables mentioned in the adoption literature for investigation business process adoption - as presented in the next section.

\subsection{Business Process Adoption}

Table 2 provides a summary of the variables that were considered relevant for the current research. This study posits that the adoption of business processes is influenced by 
individual, business process and organisational factors as shown in Figure 1. These factors are discussed briefly in the next section.

Table 2: Business Process Adoption Factors

\begin{tabular}{|c|c|c|c|}
\hline Construct & Variable & Model/Theory & Main Authors \\
\hline \multirow[t]{4}{*}{$\begin{array}{l}\text { Individual } \\
\text { Characteristics }\end{array}$} & $\begin{array}{l}\text { Personal } \\
\text { Innovativeness }\end{array}$ & & Agarwal \& Prasad [4] \\
\hline & Perceived Usefulness & Technology Acceptance Model & Davis [13] \\
\hline & Perceived Ease of Use & Technology Acceptance Model & Davis [13] \\
\hline & Attitude towards use & Theory of Reasoned Action & Fishbein and Ajzen [3] \\
\hline \multirow[t]{4}{*}{$\begin{array}{l}\text { Process } \\
\text { Characteristics }\end{array}$} & Relative Advantage & $\begin{array}{l}\text { Perceived Characteristics of } \\
\text { Innovations. }\end{array}$ & Moore \& Benbasat [22] \\
\hline & Compatibility & $\begin{array}{l}\text { Perceived Characteristics of } \\
\text { Innovations. }\end{array}$ & Moore \& Benbasat [22] \\
\hline & Complexity & $\begin{array}{l}\text { Perceived Characteristics of } \\
\text { Innovations. }\end{array}$ & Moore \& Benbasat [22] \\
\hline & Result demonstrability & $\begin{array}{l}\text { Perceived Characteristics of } \\
\text { Innovations. }\end{array}$ & Moore \& Benbasat [22] \\
\hline \multirow[t]{4}{*}{$\begin{array}{l}\text { Organisation } \\
\text { Characteristics }\end{array}$} & $\begin{array}{l}\text { Top Management } \\
\text { Support }\end{array}$ & & $\begin{array}{l}\text { Rai \& Bajwa [23]; } \\
\text { Premkumar \& Roberts [24] }\end{array}$ \\
\hline & User Participation & & $\begin{array}{l}\text { Venkatesh \& Bala [30]; } \\
\text { Adam Mahmood, Burn, } \\
\text { Gemoets \& Jacquez [1] }\end{array}$ \\
\hline & User Training & & $\begin{array}{l}\text { Ahearne, Jelinek \& Rapp } \\
\text { [2] }\end{array}$ \\
\hline & User Support & & $\begin{array}{l}\text { Schillewaerta, Ahearne, } \\
\text { Frambach \& Moenaert } \\
{[26]}\end{array}$ \\
\hline
\end{tabular}

\subsubsection{Individual Factors}

The individual factors that will be explored for the adoption of business processes were drawn from the individual technology adoption literatures as discussed in section 2.2. The factors that have been considered relevant for this study are personal innovativeness in the domain of IT, perceived usefulness, perceived ease of use and attitude towards use. These are discussed below:

Personal innovativeness is one of the key constructs that has been identified in the study of personal behaviour towards innovations. [4:206] defined personal innovativeness as "the willingness of an individual to try out any new information technology". Lu, Yao \& $\mathrm{Yu}$ [21] suggested that highly innovative individuals are active information seekers about new ideas and always look for better or easier ways of doing things. Personal innovativeness is therefore expected to have an impact on the adoption of business processes by individuals.

Perceived usefulness is defined as the degree to which a person believes that using a particular system would enhance his or her task performance [11]. Perceived usefulness has been shown to be a strong predictor of technology adoption and usage $[13,14]$. In the proposed model, it is expected that perceived usefulness will have a direct impact on the user's adoption of business processes. The main reason for users to follow or adopt a particular business process is that they perceive it to be useful.

Perceived ease of use is defined as the degree to which a person believes that using a particular system would be free from effort [13]. In TAM, perceived ease of use is associated with the behavioural intention to use a new technology. Venkatesh [29] suggested that individuals will form early perceptions of ease of use based on the anchors 
related to their beliefs regarding computers and computer use. Perceived ease of use is therefore expected to have an impact on the adoption of the business process.

Attitude is defined as an individual's positive or negative feelings about performing a behavior [3]. The attitude of users towards business processes is also expected to have an impact on the adoption of business processes. A favourable attitude is likely to result in the adoption of business process, whereas an unfavourable one is likely to result in a rejection.

\subsubsection{Process Factors}

The diffusion of innovation (DOI) theory can be considered as one of the most popular theories that has attempted to explore the factors that affect an individual to adopt a technological innovation. According to DOI, the adoption of an innovation by individuals is affected by five factors namely, relative advantage, compatibility, trialability, observability and complexity. These factors were therefore considered relevant to the understanding of business process adoption. These characteristics are summarized in the next section:

Relative advantage is one of the attributes of an innovation that has been argued to influence the adoption behaviour. Agarwal \& Prasad [4] described relative advantage as the extent to which a potential adopter considers the new innovation as offering an advantage over previous ways of performing the same task. For this study relative advantage is defined as the degree to which the user believe that following a business process will offer an advantage as compared to not following it.

Compatibility is defined as the degree to which an innovation is perceived as being consistent with the existing values, needs and past experiences of potential adopters [22]. For this study, compatibility is defined as the degree to which a business process is compatible with the user's daily activities.

Complexity is defined as the degree to which an innovation is perceived as being difficult to use [22]. The role of process complexity has been investigated in previous studies, for example Bala [8] found that higher levels of process complexity had a negative impact on the employee's job performance. In this study, complexity is defined as the degree to which the users find the business process difficult to follow. If the users perceive the business process as being complex and difficult to follow, then the user is likely to reject the business process.

Observability is defined as the degree to which the results of an innovation are observable to others [22]. If the user is able to see the benefits of following a business process, then the user is more likely to adopt the business process.

\subsubsection{Organisational Factors}

Previous studies on technology adoption and usage have acknowledged the importance of organisational factors in the successful adoption of technologies. Top management support, user training, user participation and user support are among the most widely studied organisational factors. These variables were also mentioned by Jeyaraj, Rottman \& Lacity [18] as the best predictors of technology adoption. These are discussed in the next section.

Top management support has been argued to be one of the critical factors that influence the adoption of technologies in organisations [23]. In their study, Premkumar and Roberts [24] found strong evidence for top management support as a key determinant of technology adoption. Rai and Bajwa [23] also suggested that the support of top management can assist in preventing resistance from certain individuals. Bai and Sarkis [7] added that top management support is important as they control the resources required to support projects. Based on the previous studies, the support of the top management is therefore expected to influence the adoption of business processes in organisations

User participation in the development or acquisition of technologies has been shown to have an impact on technology adoption. Venkatesh and Bala [30] defined user 
participation as the assignments, activities, and behaviors that users perform during the systems implementation process. In their study, Adam Mahmood, Burn, Gemoets and Jacquez [1] investigated the role of user participation in information technology adoption. Their findings indicated that user participation has a significant impact in the design and implementation of information technologies. The participation of the users in the design of business process is therefore expected to have an impact on the adoption.

User training has also been shown to affect the adoption of technologies in organisations. In this study, user training is defined as the degree to which the organisation has instructed people in using business processes. In their study, Schillewaerta, Ahearne, Frambach and Moenaert [26] found that user training was a strong determinant on the adoption and also enhanced the perceptions of ease of use and usefulness of the technology.

User support has been shown to have an impact on the adoption of new technologies. Ahearne, Jelinek, and Rapp [2] found that higher levels of user support were associated with higher levels of IT use whereas lower levels of support resulted in decrease in IT use which affected the productivity

\section{Developments}

Based on the literature presented in section 4, the initial BPA model as depicted in Figure 1 was proposed and a questionnaire to test this model was developed.

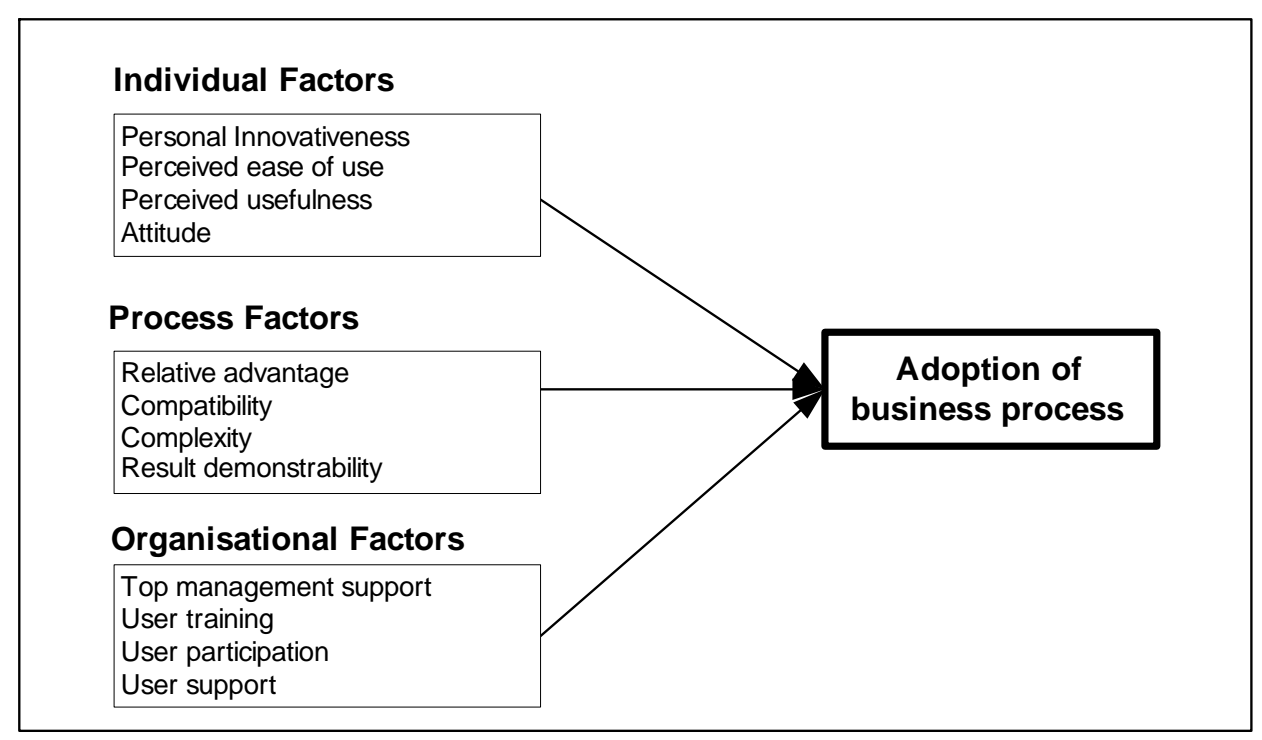

Figure 1 - Initial BPA Model

\section{Results}

The purpose of this study was to identify those factors that contribute to the adoption of business processes within an insurance organisation in South Africa. This section presents the results from individual interviews and survey. A brief description of the profile of respondents is given followed by a summary of the results and the presentation of the final model.

\subsection{Profile of the Respondents}

The interviews were conducted with eight business process analysts, four females and four males. All the participants had extensive knowledge of business processes and were all at team leader or manager level. For the survey, a total of 64 responses were received for the survey representing a $53 \%$ response rate. Respondents were asked to give information 
regarding their age, gender, employment level and department they belong to in the organization. A total of 33 participants were female and 31 were male representing 52\% and $48 \%$ respectively. The average respondents ranged from 18 to 64 years. The highest percentage of responses was 33\% which came from users between ages 25 to 34 years of age. The lowest was $2 \%$ which came from 55 to 64 years.

6.2 Interview ResultsThe interviews highlighted that some employees were not truthfully following their business processes, there was no formal training on business processes and there was lack of management support for business processes. The participants also indicated that attitude towards use was not an issue as this was linked to the employees remuneration structure. Based on the feedback from the interviews, attitude and user support were removed from the model as there was no support of these variables from the interview participants.

6.3 Survey ResultsIndividual factors: A stepwise multiple regression was conducted to evaluate whether individual factors (personal innovativeness, perceived ease of use, perceived usefulness) were able to predict business process adoption. An inspection of independent factors revealed that none of the variables were significant at $95 \%$ level of confidence. Perceived ease of use was the best predictor with a p-value of 0.12 .

Process factors: Stepwise multiple regression was also conducted to evaluate whether business process factors (relative advantage, compatibility, complexity and result demonstrability) had an impact on business process adoption. Stepwise regression revealed that compatibility was a significant predictor with a p-value of 0.03 at a $95 \%$ level of confidence.

Organisational factors: A stepwise multiple regression was conducted to examine whether organizational factors (top management support, user training and user support) had an impact on business process adoption. An inspection of independent factors revealed that top management support was a significant predictor with a p-value of 0.02 at $95 \%$ level of confidence.

In this study, adoption was not voluntary; users were mandated to adopt business processes and there were financial implications if they did not comply. Measuring adoption in mandated use situations is a challenging task and it is difficult to identify a central adoption variable. Venkatesh [30] suggest that the only question is how faithfully do users accept the new technology. Towards that end the BPA model should be tested in an expert review within the company but that is beyond the scope of this article. The contribution of this article is to propose the initial BPA model and confirm the impact of two factors namely relative advantage (process) and top management support (organizational) on business process adoption and suggest perceived ease of use as the most important individual factor.

\section{Business Benefits}

As argued in this study, business processes are critical to the success of the organization. The business benefit of this study is highlighting the factors that could affect the successful adoption of business processes. These findings indicate that managers have a role to play in ensuring appropriate support for business process adoption. The findings from this study can also be used as a guideline for improving the adoption of business processes when deploying new business processes or making changes to existing business processes.

\section{Conclusion}

This study investigated the factors that influence the adoption of business processes in insurance organisations. The results from the interviews and statistical analyses revealed 
that relative advantage and top management support were significant predictors of business process adoption in organisations. A potential limitation of this study is that the generalizability is limited by the findings being based on one company and the relatively small sample sizes in the data collection. The theoretical contribution of this study is to apply the mature technology acceptance literature to the lesser known problem of business process adoption. This research also contributes to theory by providing empirical validation of the significance of two factors impacting business process adoption and highlights the complexity of identifying a central adoption variable. A practical contribution is the offering of insights into why employees resist adopting business processes.

This study focused on one insurance organisation in South Africa, future research can build on this study by testing the BPA model proposed in other insurance organisations in South Africa and elsewhere in Africa.

\section{References}

[1] Adam Mahmood, M. O., Burn, J. M., Gemoets, L. A., \& Jacquez, C. 2000. Variables affecting information technology end-user satisfaction: a meta-analysis of the empirical literature. International Journal of Human-Computer Studies 52(4), 751-771.

[2] Ahearne, M., Jelinek, R., \& Rapp, A. 2005. Moving beyond the direct effect of SFA adoption on salesperson performance: Training and support as key moderating factors. Industrial Marketing Management, 34(4), 379-388.

[3] Ajzen, I. 1988. Attitudes, personality and behavior. Open University

[4] Agarwal, R., \& J. Prasad, J. 1997. The Role of Innovation Characteristics and Perceived Voluntariness in the Acceptance of Information Technologies. Decision Sciences 23(3), 557-582.

[5] Aldin, L., \& de Cesare, S. 2011. A literature review on business process modelling: new frontiers of reusability. Enterprise Information Systems 5(3), 359-383.

[6] Armistead, C., \& Machin, S. 1997. Implications of business process management for operations management. International Journal of Operations \& Production Management 17(9), 886-898.

[7] Bai, C., \& Sarkis, J. 2013. A grey-based DEMATEL model for evaluating business process management critical success factors. International Journal of Production Economics 146(1), 281-292.

[8] Bala, H. 2013. The effects of IT-enabled supply chain process change on job and process outcomes: A longitudinal investigation. Journal of Operations Management 31(6), 450-473.

[9] Bititci, U. S., Ackermann, F., Ates, A., Davies, J., Garengo, P., Gibb, S., MacBryde, J., Mackay, D., Maguire, C., van der Meer, R., Shafti, F., Bourne, M., \& Firat, S. U. 2011. Managerial processes: business process that sustain performance. International Journal of Operations \& Production Management 31(8), 851-891.

[10] Chan, S. L. 2000. Information technology in business processes. Business Process Management Journal 6(3), 224-237.

[11] Childe, S. J., Maull, R. S., \& Bennett, J. 1994. Frameworks for understanding business process reengineering. International Journal of Operations \& Production Management 14(12), 22-34.

[12] Damij, N., Damij, T., Grad, J., \& Jelenc, F. 2008. A methodology for business process improvement and IS development. Information and software technology 50(11), 1127-1141.

[13] Davis, F. D. 1989. Perceived Usefulness, Perceived Ease of Use, and User Acceptance of Information Technology. MIS Quarterly 13(3), 319-340.

[14] Davis, F. D., Bagozzi, R. P., \& Warshaw, P. R. 1989. User acceptance of computer technology: a comparison of two theoretical models. Management Science 35(8), 982-1003.

[15] Gaivin, D. A. 1998. The Processes of Organisation and Management. Sloan Management Review 39(4): 33-50.

[16] Hess, T. J., Joshi, K., \& McNab, A. L. 2010. An alternative lens for understanding technology acceptance: an equity comparison perspective. Journal of Organisational Computing and Electronic Commerce 20(2), 123-154.

[17] Janićijević, N. 2010. Business processes in organizational diagnosis. Journal of Contemporary Management 15(2), 85-106.

[18] Jeyaraj, A., Rottman, J. W., \& Lacity, M. C. (2006). "A review of the predictors, linkages, and biases in IT innovation adoption research." Journal of Information Technology 21(1): 1-23.

[19] Lindsay, A., Downs, D., \& Lunn, K. 2003. Business processes—attempts to find a definition. Information and Software Technology 45(15), 1015-1019.

[20] Lohmann, N. 2013. Compliance by design for artifact-centric business processes. Information Systems 38(4), 606-618. 
[21] Lu, J., Yao, J. E., \& Yu, C. S. 2005. Personal innovativeness, social influences and adoption of wireless Internet services via mobile technology. The Journal of Strategic Information Systems 14(3), 245-268.

[22] Moore, G. C., \& Benbasat, I. 1991. Development of an instrument to measure the perceptions of adopting an information technology innovation. Information Systems Research 2(3), 192-222.

[23] Rai, A., \& Bajwa, D. S. 1997. An Empirical Investigation into Factors Relating to the Adoption of Executive Information Systems: An Analysis of EIS for Collaboration and Decision Support. Decision Sciences, 28(4): 939-974.

[24] Premkumar, G., \& Roberts, M. 1999. Adoption of new information technologies in rural small businesses. Omega 27(4), 467-484.

[25] Scherr, A. L. 1993. A new approach to business processes. IBM Systems Journal 32(1), 80-98.

[26] Schillewaert, N., Ahearne, M. J., Frambach, R. T., \& Moenaert, R. K. 2005. The adoption of information technology in the sales force. Industrial Marketing Management 34(4), 323-336.

[27] Singh, P. K. 2012. Management of Business Processes Can Help an Organization Achieve Competitive Advantage. International Management Review 8(2), 19-26.

[28] Strnadl, C. F. 2006. Aligning Business and IT: The Process-Driven Architecture Model. Information Systems Management 23(4), 67-77.

[29] Venkatesh, V. 2006. Where To Go From Here? Thoughts on Future Directions for Research on Individual-Level Technology Adoption with a Focus on Decision Making. Decision Sciences 37(4), 497518.

[30] Venkatesh, V., \& Bala, H. 2007. Adoption of Interorganizational Business Process Standards in Business-to-Bus. Systèmes d'Information et Management 12(2), 53-111.

[31] Venkatesh, V., \& Davis, F. D. 2000. A Theoretical Extension of the Technology Acceptance Model: Four Longitudinal Field Studies. Management Sciences 46(2),186-204.

[32] Venkatesh, V., Morris, M. G., Davis, G. B., \& Davis, F. D. 2003. User acceptance of Information Technology: Toward a unified view. MIS Quarterly 27(3), 425-478.

[33] Visser, M., van Biljon, J., \& Herselman, M. 2012. Modeling management information systems' success: a study in the domain of further education and training. In Proceedings of the South African Institute for Computer Scientists and Information Technologists Conference, 384-393.

[34] Völkner, P., \& Werners, B. (2000). A decision support system for business process planning. European Journal of Operational Research 125(3), 633-647.

[35] Weber, B., Mutschler, B, \& Reichert, M. 2010. Investigating the effort of using business processes management technology: Results from a controlled experiment. Science of Computer Programming 75, 292-310. 